\title{
Explorations in Promoting Conceptual Change in Electrical Concepts Via Ontological Category Shift
}

\author{
Yeung LEE \& Nancy LAW \\ University of Hong Kong
}

\begin{abstract}
Chi (1992; Chi 1993; Chi et al.(1994)) suggests that much of the difficulties encountered by students in learning some Physics concepts arise because they attribute these concepts with the ontology of material substances while these concepts are actually a special type of process - "Constraint-Based Interactions”. Slotta \& Chi (1996) also reported on a study where a group of students explicitly trained in the CBI ontology showed significant gains over a control group in problem solving performance in eight simple electric circuit problems. This paper reports on a series of four studies aimed at exploring the usefulness of the ontological categorization framework in investigating students' alternative conceptions of electric circuits and in developing a teaching strategy for promoting conceptual change in the learning of basic electric circuitry concepts.
\end{abstract}

\section{Introduction}

For more than two decades, students' ideas in science prior to formal instruction have become a major concern among researches in science education. Numerous research on a large number of topics have been published (Carmichael et. al., 1990; Pfundt \& Duit, 1991; Wandersee, Mintzes \& Novak, 1994). Substantial evidence thus accumulated has indicated that students have already acquired considerable knowledge and ideas about the natural and technological world before any formal instruction had taken place. More importantly, some of these intuitive conceptions are found to differ from the accepted scientific views and were 
labelled in the science education literature variously as misconceptions (e.g. Helm, 1980), preconceptions (e.g. Novak, 1977), alternative conceptions (Driver \& Easley 1978) or children's science (Gilbert, Osborne \& Fensham, 1982). Furthermore, these intuitive conceptions were found to be extremely robust to change and were often held intact by children and adults alike even after completion of years of formal science instructions. Thus the problem of how to bring about conceptual change in learners becomes a major challenge to science educators.

Different instructional strategies to promote conceptual change have been reported. Two major approaches to fostering conceptual change are conceptual conflict strategy (Posner et. al. (1982)) and analogical reasoning Lawson (1993). Unfortunately, research studies using these two approaches have not arrived at conclusive findings. Even when students were confronted with contradictory information under the same environment, conceptual changes do not necessarily take place (Champagne, Gunstone \& Klopfer, 1985; Dreyfus, Jungwirth \& Eliovitch, 1990; Wang \& Andre, 1991). A number of studies have demonstrated that by using analogies, students can be helped to learn difficult concepts (Brown,1987; Clement, 1987; Gentner \& Gentner, 1983). However, only a limited number of successful analogies have been reported. How to generate a good analogy to suit every case is still very much a challenge (Clements, 1993); and it has also been found that the use of analogies do not always produce the intended results (Treagust, 1995).

Why is conceptual change so difficult in the learning of science concepts? What are the barriers to change ? Chi et. al. (1994) suggested that the most difficult changes are those that involve ontological re-categorisation and their theory has three important claims. The first is an epistemological claim which proposes that all entities in the world belong to three primary 
ontological categories: "matter", "processes" and "mental states". When a new concept is learned, it is associated with a particular ontology, which helps the learners to understand the nature of the concept involved and the attributes that it may possess. The second of their claims is a metaphysical one arguing that many scientific concepts are 'constraint based interactions', which is a subcategory of processes in which a defined system behaves according to the principled interaction of two or more constraints. The third claim is a psychological one, proposing that many alternative conceptions belong to the "matter" category and that learning in these instances requires a shift in the concepts' ontological status from the matter category to the process category. Chi et. al. (1994) further suggested that the major barrier to conceptual change relates to the difficulty in making the shift between two distinct ontological categories and argued that students should be taught explicitly about the constraint-based interactions and their characteristics in order to foster conceptual change in students.

In order to test these claims, Slotta, Chi and Joram (1995) investigated the explanation given by 9 novices and 4 experts in solving some problems involving physics concepts (on light, heat and electrical current) and another set of problems similar in structure involving material substances. They found that experts can use the process predicates in explaining physics problems and matter predicates in explaining material substance problems while novices commit themselves to use the matter based predicates in explaining both the physics and material substance problems. More recently, Slotta and Chi (1996) reported on a study where they found that students who had completed a training module on constraint-based interactions (CBI) were more able to conceptualize electrical concepts as CBI (i.e. process) rather than as matter compared to a control group that did not have the training. 
In short, we found that Chi et al.'s theory provided a plausible explanation for the robustness of alternative conceptions in science, as well as a framework for assessing and promoting conceptual change in the learning of science. However, Slotta and Chi (1996) did not provide any clear evidence that conceptual changed had occurred in their subjects and it is also not clear that the knowledge about CBI helped to promote whatever change that occurred. The study reported here has two main objectives: (1) To find out students' alternative conceptions on simple electric circuits and to confirm whether there exist significant differences in ontological categorization between the understanding of those who mastered the accepted elementary circuitry concepts and those who held the common alternative conceptions; (2) to explore how Chi et. al.'s (1994) theory may be used to develop a teaching strategy for promoting conceptual change. Initially only two studies were planned, the first one to address the first research question and to gain operational familiarity with the concept of CBI. The second study was planned to address the second research question if the first study led to a confirmation of the plausibility of the theory. Subsequent to these two studies, two more studies were conducted to further the exploration for an effective teaching strategy. The design and results from these four studies are reported below

\section{Study 1}

Research design

In study 1 , six secondary 6 science stream students (17 yr. olds) from a secondary school in Hong Kong who were taught elementary circuitry concepts were invited to take part in this study. The school is of average academic standard in Hong Kong. These students were selected so that two were academic high achievers (S1, S2), two were average achievers (S3, 
S4) and two were low achievers (S5, S6). The study consisted of two components, a pencil and paper test and an oral interview.

The paper and pencil test

The pencil and paper test (Appendix A) was designed to elicit students' alternative conceptions of electric circuits. It consisted of nine problems drawn from three published studies, Cosgrove(1983), Law (1991), and Shipstone (1984) that were known to elicit pertinent alternative conceptions. These questions required students to (a) compare the size of current at different points in a circuit, (b) compare the brightness of the bulbs in the same circuit, (c) compare the brightness of bulbs in different circuits, and (d) predict what would happen to the brightness of a bulb if a change was made to the circuit (by adding or removing a bulb in the circuit).

\section{[Insert table 1 about here]}

As can be seen from the results in Table 1, there is a large difference in test performance among this group of students. In order to gain a better understanding of how the students reasoned about the different circuits to arrive at their answers and to find out whether there was a distinction between the different conceptualizations in terms of ontological categories, a semi-structured interview was conducted with each student individually after the test.

\section{The semi-structured interview}

The students were invited to take part in an interview shortly after the test was completed. Each interview took about 20 to 30 minutes. During the interview, each student was asked to 
go through his/her own answer script and explain how he/she arrived at the answer. The students were not informed of the correct answer nor their own performance in the test.

The interview protocol revealed that the students still held a number of the alternative conceptions frequently documented in the research literature, even after formal instruction. Five out of the six subjects still believed that the battery was the source of current and treated the current flowing from the battery as being unaffected by changes in the external circuit. In fact, the following alternative conceptions were common amongst the subjects:

1. A battery is a source of current.

2. A battery releases a fixed amount of current.

3. Bulbs use up or consume current.

4. Current is used up by the components in the circuit.

5. The further away the bulb is from the battery, the dimmer it will be.

6. In a parallel circuit, current is divided into equal parts.

During the course of the interviews, we observed the students struggling with some conceptual conflicts between the learnt ideas and their intuitive concepts - frequently with the result of the alternative conceptions displacing the learnt ideas. For example, in comparing the current at three different points on a series circuit as shown in Figure 1, a student explained why the current should be smaller as the points were further removed from the positive terminal of the battery:

"It is because current is used up by the bulbs. Um... wait...it should be the same. Because...it is a series...Oh! No, it should be $1>2>3$. The reason is current is used up by the bulbs.” 
<insert figure $1>$

Ontological categorization of student's alternative conceptions.

The interview protocols were segmented into idea units and each unit was then coded into three categories according to the conceptual attributes of the unit as described by Chi et al. (1994): 'M'- Matter based, 'C'- Constraints based interaction and 'E' - Event. Both 'C' and 'E’ are subcategories of processes.

The following is a typical example of idea units coded as belonging to the " $\mathrm{M}$ ” ontology:

Current comes out from the battery and is used up by the bulb.

Current is divided into Two equal parts in this parallel circuit.

The underlined predicates were taken as evidence that the student conceptualized current as matter and that this idea unit should be coded as ' $\mathrm{M}$ '.

Two typical examples of idea units that were coded in the ' $\mathrm{C}$ ' category are:

The total resistance in the circuit is smaller and voltage is unchanged, therefore current will increase.

Due to the reason that $V=I R$. The (total) resistance in circuit 2 is larger, so the current is smaller.

These explanations were coded as ' $\mathrm{C}$ ' because electric current was conceptualized as the result of an interaction in a system.

A clause such as 'current flows from the positive terminal to the negative terminal' was coded as ' $\mathrm{E}$ ' because it has a beginning and an ending. 
It was found that all the relevant idea units could be categorized into these three categories. As a coding reliability check, the protocol from S5 was coded independently by two coders and the inter-coder reliability was found to be $84.5 \%$. It was pleasing to find that the results indicated that there was a clear relationship between the test performance and the ontological categories of the students' expressed conceptions. The student with the best test performance (S1) and least affected by the common alternative conceptions (according to a protocol analysis of the interview data) was also found to use CBI often in reasoning about circuit phenomena. On the other hand, students who performed poorly reason about circuitry concepts as matter.

\section{[Insert figure 2 about here]}

In short, in Study 1, we discovered that students with a higher test score tend to consider a circuit as a system where a change at any one point affects the parameters in the rest of the circuit. For example, in answering whether the location of a bulb in a series circuit will affect the speed of the motor (appendix A question 5b), Student 1 said:

"Circuit 3 is the same as circuit 2. It is because the total resistance is the same regardless of whether you put the bulb before or after the motor. Therefore, the speed of the motor will be slower.”

In addition to this the highest achiever also focus his attention on voltage when solving these circuitry problems. 
On the other hand, students with lower scores tended to reason about the circuit by analyzing it segment by segment and did not see it as a whole system. For instance, in answering the same question (5b) Student 6 said:

"The speed of the motor will increase when compared with circuit 2. It is because in circuit 2 some current is used up by the bulb. However, in circuit 3 current flows through the motor first."

\section{Study 2}

\section{Research design}

After confirming that the ontological attributes of conceptual entities used by a learner in reasoning about electrical phenomena was an important determinant of the learners' ability to master the correct scientific concepts, study 2 was an attempt to develop an effective means of promoting conceptual change through encouraging learners to reason using CBI. Unlike the Slotta and Chi (1996) study where the focus was to find out whether students who had completed a training module on constraint-based interactions (CBI) were more able to conceptualize electrical concepts as CBI, this study wanted to find out what may promote such a change, if at all, and whether and how would such a change lead to conceptual change. In view of the fact that we are still unfamiliar with promoting change in conceptual categorization, we decided that this study should be an exploratory one, working with welldocumented conceptual change methodologies.

In study 2, students working in groups were first presented with a series of "Predict-ObserveExplain” (POE) tasks (White \& Gunstone, 1992) that modelled closely the questions used in the pencil and paper test used in Study 1 (appendixB). Most importantly the students were 
encouraged to work in groups to provide self-generated analogies to explain the observed phenomena. The selected POE tasks were designed to cause cognitive conflicts so that observations can be made to examine the ways in which the students responded to those conflicts. In particular, how did they use the self-generated analogies to resolve these conflicts?

The reason for using self-generated analogies was that it can stimulate abstract thinking about underlying structures or patterns and give a fuller understanding of student's reasoning processes (Wong 1993). Chi (1989) also mentioned that self-generated analogies cause students to uncover gaps in their knowledge and to bridge them. Cosgrove (1995) also found that it was possible for students to generate analogies that help in the learning of circuitry theory. He reported on students first generating a coal truck analogy to explain the current in a simple circuit and then further developing that into a coal train analogy which helped the students to rectify the consumption model of current they held earlier. He also asserted that "The ownership of the analogy and the frows with the development of analogy itself as a part of the process of making sense of the phenomenon?" It is hope that through the self-generated analogies and the social co-construction processes afforded by the discussion of such analogies, students would change towards the scientifically accepted conception and in that process also change to thinking about circuitry phenomena as constraint-based interactions. In study 2 we dealt with the following concepts:

1. Current is conserved and not 'used up' by the circuit components.

2. A cell is not a source of constant current.

3. The amount of current in a circuit is dependent both on the circuit components and the configuration of the circuit. 
Two groups of students took part in Study 2: a group of three secondary 6 students with the lowest test scores in the pencil and paper test in Study 1 and another group of six students from a secondary 4 science class (15-year-olds) who had not learnt elementary circuit theory. All verbal data was audio-recorded during each session, fully transcribed and analyzed to identify:

1. The individual self-generated analogies and explanations given by each student for the observed circuit phenomena; and

2. The self-generated analogies that were modified or abandoned in the course of the group discussions as a result of social construction and the reasoning processes involved.

\section{The self-generated analogies}

At the start of the session, students were asked to predict and observe the current at different points in a series circuit (figure 3) and to generate analogies to explain their observations.

\section{(insert figure 3)}

It was found that both groups of students generated similar analogies for their explanations when they were confronted with the experimental result. As a result five interesting analogies were found at the beginning of the study:

1. Current is like a group of people, the bulb is like a subway. (2 students):

"It is like a group of people walking through a subway. The same numbers of people enter the subway and leave the subway. Therefore, current is the same in a series circuit."

2. Current is like a bus transporting people from one place to another. (2 students): 
"Current is like a bus picking up people at the station (battery) and putting them down at the bus stop (bulb) then going back to the station.”

3. It is like a man jumping over a hurdle. (1 student)

"Current is like a man jumping over a hurdle (bulb). In this whole process the number of men will not change. Therefore, current is the same in a series circuit.”

4. It is like a man taking a bowl of rice (energy) to feed the cat (bulb). Therefore, it will only lose energy, not current. Thus, current should be the same in a series circuit. (2 students)

5. Current is like a lorry, the bulb is like the customer. (2 students)

"It is like a lorry delivering goods (energy) to the customer. Therefore, current is the same, the bulb only used up energy not the current."

From these self-generated analogies, it is evident that the students were drawing on their day to day experience in trying to understand the observed phenomenon, and that all these analogies construed current as matter rather than as a process. These analogies only focussed on surface similarities but had not tried to address the underlying mechanism leading to the observed phenomenon.

\section{Conceptual development through group discussion}

It was observed that throughout the subsequent discussion, students evaluated, modified and abandoned some of the analogies. The discussion process provided students with an opportunity to challenge and to refine the analogies they have created. 
The following excerpt taken from the Secondary 4 students' discussion in explaining the different currents flowing in the two series circuits in Figure 4, provides a typical example of the kind of social co-construction that took place:

Student 1: The current in circuit 2 is smaller. It is like a crowd of man jumping over the hurdles. After they had finished the first round, some of them quit because it is too difficult for them to jump over the two hurdles.

Student 2: That means there will be difference between the current measured at the first time and second time.

Student 3: But how do you know the current that you are measuring is in the first, or second or the third round?

Student 4: Yes, yes, how do you measure it?

Student 1: Maybe... maybe there is a problem... it is difficult to figure out. Maybe this analogy is not suitable. Let me think of another one.

$<$ insert figure 5>

It is interesting to note that when students were asked to compare the brightness of the bulbs in the same circuit, whether for bulbs in series or in parallel, they construed current as matter:

(Discussing circuit 2 in figure 4)

The brightness of bulb A and bulb B is the same because current is the same. It is like a man jumping over A hurdle. In the whole process the number of men will not change.

(explaining circuit with two bulbs in parallel)

Branch A and Branch B are like roads. Bulb A and bulb B are like the hurdles. Therefore, in parallel circuit the two roads (branch) are of the same level of difficulty, so the same numbers of men (current) pass through each branch. As a result, the brightness of bulb A and bulb B is the same.' 
However, when students were asked to compare the current between two different circuits or the current in the same circuit before and after some changes were made, it stimulated the students to change their focus of attention and subsequently their analogies. The following excerpt is one such example:

(Comparing the current between different circuits)

Teacher: $\quad$ Compare the amount of current in circuit 1 and 2 (referring to figure 4.)

Student 1: The current in both circuits is the same. Because the battery gives a fixed amount of current. It is like having a lorry carrying goods in each circuit.

Students 2: No, there are 2 bulbs in circuit 2, so more current is needed.

Students 3: I do not agree with you. current is not used up as we have discussed before. It is only the energy, which is used up. Referring to the analogy, it is the goods that have been delivered. Therefore, current is the same in both circuits.

Students 2: Yes, you are right.

Teacher: $\quad$ Now set up the circuit and measure the current.

Student 1: It is strange, current in circuit 2 is smaller.

Student 3: I think maybe in circuit 1, the lorry only needs to stop once to load down the goods, but in circuit 2 the lorry needs to stop twice to load down the goods. Therefore, the speed is slower.

Student 2: That means current is the speed of the lorry not the lorry itself.

Student 1: Yes, it may be the speed of the lorry. Hey! That means although there is one battery in both circuits, it does not give out the same amount of current. The amount of current is dependent on the number of bulbs in the circuit.

Student 2: Ah! yes, in circuit 2 the resistance is larger so the current is smaller.

Compare current in the same circuit after some changes (Appendix D, teaching sequence 9)

If the switch is closed current will become larger because there is only one hurdle (bulb) on the road. So it takes less time to finish the whole journey. In other words, the speed of the man is faster. Thus, current is larger. 
It is evident from the above excerpt that co-construction of meaning occurred during students' interactions (discussion) and that they were able to revise their analogies to provide for an underlying mechanism - the speed of the lorry when interpreting the meaning of current. It is important to note that speed is a dynamic descriptor pertaining to the behaviour of the system, rather than an uni-dimensional measure of a particular component. Thus current is now no longer construed as matter but as a process - a constraint-based interaction.

While it was pleasing to find that both groups of students were able to refine their analogies through group discussion and to move towards CBI reasoning, their attention was focussed on current all the time and were not able to move further towards the accepted scientific view

\section{Summary}

Study 2 provided evidence that: (1) students can produce and use self-generated analogies in explaining some simple circuit phenomena and communicate their understanding to others; (2) through socio-cognitive interactions in group discussions, students can develop a better understanding of circuit phenomena; (3) using POE tasks involving two different circuit arrangements or a change in the circuit setting, students can be encouraged to modify their analogies and to move towards CBI reasoning; and (4) the POE tasks used in this study only encouraged students to focus on current and not on voltage, even for the secondary 6 students who had learnt this concept before, thus hindering progress towards constructing the scientifically accepted understanding of circuitry concepts even when they can use CBI reasoning for interpreting current. 


\section{Study 3}

As a result of our findings from study 2, we generated a hypothesis: in order to have conceptual change, students should be guided not only to reason in terms of constraint based interactions, but they should also be guided to focus on the appropriate constraint. In order to seek evidence for this hypothesis- we decided to conduct Study 3.

\section{Research design}

The subjects were the same as those in Study 2 except for one of the secondary 6 students.

The process used in this study is similar to that in Study 2 except that the POE tasks were redesigned to draw attention to variations in voltage rather than resistance as in the previous study. Thus instead of adding a resistance in different configurations to the circuit, a battery was added. After putting in an additional battery in series and in parallel to the battery in the initial simple circuit (in the same direction and then in opposition to the original battery orientation), students were asked to predict, observe and explain: (a) the brightness of the bulbs in the modified circuit, (b) the measured voltage in the circuit, (c) the size of the current at different points in the circuit, and (d) the comparative brightness of the bulbs in the different circuits. The main goal for these activities was to help students to build up a conception of voltage as a key constraint on current flow and that it has both direction and magnitude. (For details of the task specification please refer to Appendix C). It is hoped that by guiding students to shift their focus to voltage as the primary constraint, a better understanding of circuit theory can be brought about.

Process-oriented Analogies generated by students. 
During the sessions, both the secondary 4 and secondary 6 students were able to generate process-oriented analysis in their attempts to interpret voltage

1. It is like a push.

At the beginning of the lesson when students were asked the role of the battery in the circuit it was found that students in both groups tend to consider the battery as a pump and voltage as a push or a force. The following excerpts drawn from the two group discussions illustrate their thinking clearly:

(Excerpt drawn from secondary 6 students)

Researcher: This is a battery. What is the use of it in a circuit?

Student 1: $\quad$ It acts as a power supply.

Student 2: $\quad$ Yes, it provides electrical energy. It is like a pump.

Researcher: What do you mean by it acts like a pump?

Student 1: $\quad$ To pump out the electrons.

Researcher: Do you mean that electrons are stored inside the battery?

Student 1: $\quad$ Um...

Student 1: $\quad$ No, electrons are not stored insides the battery.

Student 2: $\quad$ No, I think they are not stored inside the cell. Electrons are in the whole circuit. The cell provides a push for the electrons.

Student 1: $\quad$ Yes, it is like a pump to give a push to the electrons.

Student 2: $\quad$ I agree

(Excerpt drawn from secondary 4 students)

Researcher: What do batteries do to the circuit?

Student 1: $\quad$ They produce electrical energy to the circuit.

Student 2: $\quad$ They give electric current to the circuit.

Student 3: $\quad$ They help electrons to move round the circuit. It is like a pump.

Student 4: $\quad$ Yes, I agree. They give a push for the electrons to move. 
2. It is like water in two vessels

When students were asked to explain the concept of voltage one of the secondary 4 students use a water analogy in explaining the potential difference between the positive and negative terminal.

Let us assume that the positive and negative terminals are two vessels and there is water in both of them. One vessel has a higher water level and the other one has a lower water level. The vessels are joined with a pipe. Thus water in the higher level will flow to the lower level until it reaches the equilibrium condition.

3. It is like a tug- of- war

In explaining the voltage across two cells which were connected in series in opposite directions (appendix C, circuit 5), one of the secondary 6 students referred to it as a tugof-war:

Voltage across the two cells is 0 and across each cell is $1.5 \mathrm{~V}$. It is like a tug-of-war. Each group gives out the same amount of force. However, the rope does not move. It seems that no force is acting on it but actually there is.

4. It is like a ramp.

In comparing the voltage across two cells connected in series and connected in parallel (appendix C circuit 4 and 5), one of the secondary 4 students referred to it as a ramp: ... In circuit 2, the two cells connected in series are like a road with a greater slope. In circuit 4, the two cells are connected in parallel and they are like two roads with a smaller slope. If a ball is put at the top of the steeper road, then the push becomes larger and more energy transfers per unit time... 
It is evident from the above excerpts that by focusing the students' attention on varying configurations of batteries, students are encouraged to think about the mechanisms underlying the observed circuit behaviour. Hence even the analogies generated at the beginning of the POE tasks all belong to the category of processes compared to the matter based analogies which were generated at the beginning of the POE tasks in Study 2. The analogies involving 'push', 'force' and 'tug-of-war' were all concerned with processes even though it is not clear whether they were thinking in terms of constraint-based interactions or not. Moreover, the ‘ramp’ analogy provided an opportunity for visualizing the concept of potential difference.

Secondary 4 students' reasoning about voltage.

As evident from the previous discussion students in both groups referred to voltage as a push or a force that caused electrons to flow (details are shown in previous section). However, the understandings achieved by the two groups of students in this study were very different as they moved on to reason further about specific circuit configurations.

When the secondary 4 students who had not been taught the concept of voltage before were asked to explain their predictions or observed variations in voltage across the batteries and the bulbs, The analogies they generated did not always belong to the category of processes. Three interesting ways of reasoning belong to the matter oriented analogies were identified:

a. Annihilation model.

When students were asked to explain why the voltage across two batteries connected in opposite directions was zero (appendix C, circuit 5), they hypothesized that some form of annihilation involving electrons was at work:

The electrons collide with each other and then die and disappear. 
The electrons come out from each cell and they are facing each other when they meet. They then collide with each other like a spark and disappear.

b. Additive model

When asked to predict the voltage across the batteries when connected in parallel (appendix C circuit 4), four of the six secondary 4 students believed that as the number of batteries increased, the voltage would also increase. This indicates that students could not distinguish this situation from the case when the batteries were connected in series

I think circuit 2(two batteries connected in series) and 4(two batteries connected in parallel) are the same. It is because in circuit 2 it had two pumps and (circuit) 4 also had two pumps. The speed is the same although in circuit 4 the wire is a little bit longer.

Circuit 4 (two batteries connected in parallel) and 2(two batteries connected in series) are the same. Because the set up is similar.(2cells)

c. Strength of push model

When students were asked to predict the voltage across each bulb for a circuit with two bulbs connected in series (appendix C, circuit 6), they predicted that it would be equal to the voltage of the battery as the strength of push going through the circuit should be the same:

Voltage across each bulb is $1.5 \mathrm{~V}$ because the magnitude of the push throughout the circuit is the same so bulb A and bulb B is the same. It is $1.5 \mathrm{~V}$. 
It is evident from the above observations that the secondary 4 students are still not able to understand the concept of voltage as potential difference and that they are still prone to resort to matter attributes to reasoning about unfamiliar situations. All the three models involve some ways of thinking in terms of matter: in the annihilation model, it is electrons as matter that cancel each other; in the additive model, push can be simply added together as in matter; and in last model, push is conceptualized as something that is transmitted through the circuit. However, it is also important to note that in these analogies, the students were very much thinking about the circuit as a system rather than as isolated parts that could be dealt with in sequential manner. This is a very significant difference from the case in Study 2 when the focus was on currents. Using a systems approach to reason about mechanisms is a very important characteristic of scientific reasoning and this provides a much easier route to understanding or reasoning in terms of constraint based interactions.

It was also observed that when students had an opportunity to measure the voltage across the batteries and bulbs, they quickly abandoned the additive model and the strength of push model in their reasoning. Unfortunately, these secondary 4 students did not have further information to rely on to move further in creating an understanding involving constraintbased interactions.

\section{Secondary 6 students' reasoning about voltage.}

The progress made by the secondary 6 students were remarkable when asked to reason about the voltage in different parts of the circuit. First of all, they were all able to predict correctly the voltage across the different circuit elements as required by the set tasks. It thus appears that the students found greater difficulty in predicting the correct current in the earlier set of POE tasks in Study 2 than predicting the correct voltage that would be observed in the POE 
tasks in Study 3 even though the circuits in Study 2 should be more familiar to them. Secondly, it was found that the secondary 6 students very quickly made use of the water analogy to reason about the voltages and solved the problems smoothly and correctly. We found that their prior knowledge of Ohm's Law formed the basis of their predictions and explanations about the circuit phenomena in terms of constraint based interactions. Finally, it is pleasing that the S6 students no longer generated matter based analogies. The analogies they generated all belonged to the process ontology. Apart from this, they were also found to be able to use Ohm's law to solve the problems correctly.

\section{Summary}

The results of this Study indicate that by guiding students to focus on variation of voltage in circuits with different battery configurations, it encourages students to think in terms of processes and to use a systems approach in reasoning about circuit phenomena. However, for students to move successfully towards using CBI reasoning, it appears that the knowledge of Ohm's Law is also crucial. We thus hypothesized that the Secondary 4 students' ignorance about Ohm's law led to a knowledge gap in their cognitive repertoire so that they were not able to create the exact constraint condition to make adequate use of CBI reasoning.

\section{Study 4}

The results from the previous three studies helped us to refine and modifying our hypothesis: in order to promote conceptual change, students should be (1) guided to reason in terms of constraint based interactions, (2) guided to focus their attention on a critical constraint that encourages learners to reason in a systems manner, and (3) provided with the knowledge of 
the exact constraint condition - Ohm's law. In order to seek further evidence for our hypothesis, we decided to conduct study 4 as a teaching experiment for a group of 6 secondary 4 students who had not been taught elementary circuit theory and had so far not been involved in this series of studies.

\section{Research design}

This study comprised a pen and paper pretest and posttest and a teaching sequence of 4 lessons that made use of a combination of hands-on experiments, POE tasks and analogical discussions adapted from those used in Study 3. Lesson 1 focussed on helping students to construct an understanding of the concept of voltage using the POE tasks involving the prediction of voltage for different battery configurations. Concepts involved in this lesson were as follows:

1. The primary constraint on current flow is voltage

2. Voltage has both direction and magnitude

3. The size of the push on current depends on the voltage of the battery as well as the configuration of the batteries in the circuit.

One main difference from the treatment used in Study 3 was that after some initial discussions, the students were explicitly introduced to the water pump analogy (similar to that used by Hewitt (1987) and Gentner \& Gentner (1983) with water pressure, flow of water, constricted pipes and pump representing voltage, electric current, resistance and battery respectively) for thinking about batteries and voltages. This change was made on the basis that some form of water analogy was found to be often generated spontaneously by students in the previous studies and that it was also the most fruitful analogy that the secondary 6 students used in their reasoning process in Study 3. 
Lesson 2 began with observations of different brightnesses for bulbs of different internal resistances. Students were asked to give an explanation for the variation in brightness and also introduced to the measurement of current using ammeters. The rest of the lesson consisted of POE tasks involving the prediction of the voltage across and the brightness of each bulb in different circuit configurations involving one or two batteries and one or two light bulbs. Throughout this exercise, students were encouraged to provide explanations using the water pump analogy. Concepts involved in this lesson were:

1. The concept of resistance

2. The sharing of voltage across components in a series circuit

3. For a series circuit, bulbs with a larger resistance will have a greater voltage across it.

4. Voltage across each branch of a parallel circuit is the same

5. The relationship between voltage, current and resistance in a circuit

In short, the main purpose of this lesson was to introduce the concepts of voltage, resistance and current and to develop an understanding of the interdependence of these three parameters with voltage as the key determining parameter.

Lesson 3 began with the introduction to Ohm's Law through asking students to measure current for varying voltages (by varying number of batteries) and to plot voltage against current. At this point, students should have the necessary knowledge to adequately reason about circuit phenomena using CBI. The second half of this lesson comprised of POE tasks involving the prediction of current for two circuits, one involving two resistors in series and the other two resistors in parallel. This part of the lesson not only provided an opportunity for the students to practice reasoning with CBI but also to be introduced to the concept of equivalent resistance for different combinations of resistances. The concept of equivalent 
resistance should lead to a more in-depth understanding of the systems nature of electrical circuits and a better understanding of Ohm's Law as a constraint.

Lesson 4 was essentially an exercise for consolidation. Students were presented with further POE tasks involving complex circuit configurations containing both series and parallel circuit segments.

A pencil-and-paper test similar to that administered in Study 1(appendix D) was presented to this group of students as pre- and post- tests. Individual interviews with the students were also conducted after both the pre-test and the post-test so as to find out whether this teaching sequence had been successful in bringing about conceptual change.

\section{Alternative conceptions held by the participating group of secondary 4 students}

From the pre-test interviews and the pencil-and-paper test, it was found that all the alternative conceptions uncovered in study 1 were also found amongst this group of secondary 4 students. The interview data revealed that all 6 students used sequential reasoning in their explanations. In addition, the students tended to use the words 'electricity' and 'electric current” interchangeably (for example, a student said, “.... because electricity flows from the positive to the negative terminal.") Students also tended to associate "electricity" with energy consumption and this concept definitely possesses the attributes of the matter ontology. For example, in responding to a question about the brightness of the bulbs in a series circuit in the pre-test, a student said: "Because electricity flows from the positive to the negative terminal and passes through bulb A, bulb A uses up some electricity, so bulb B gets less electricity. Therefore, bulb B is dimmer." Furthermore, some students believed that the brightness of the bulb was predetermined by the nature of the bulb and that the current consumed by a bulb was 
an intrinsic attribute of the bulb concerned irrespective of the circuit configuration. They simply viewed each bulb in the circuit as using a constant amount of current. The interview data also revealed that the students were all focusing on current in their reasoning.

\section{Conceptual development during the teaching process}

Analysis of the students' discussions during the sequence of lessons seems to indicate that the intended conceptual development did take place pretty much as expected. In Lesson 1, the students generated the idea that the battery provided the push for the electrons to flow, started to focus their attention on voltage and were also able to make use of the water pump analogy to think about current as a flow of electrons. An example of the students' responses is as follows:

Before teaching: It [the battery] is an electricity source.

After teaching: Yes, the battery provides a push for the electrons to flow, it acts like a pump.

As the sequence of lessons progressed, similar to observations made in study 3, the students exhibited the ability to give up sequential reasoning and became aware that the circuit configuration is as important as the number of circuit elements. Following is an example illustrating their awareness of the importance of circuit configuration:

Researcher: Compare the voltage across the batteries in circuit 4 and 1. (Figure 5)

Student 6: Voltage in circuit 4 will be larger. It is because there are two cells in this circuit.

Student 2: I think voltage in circuit 4 is larger because there are two cells and they will supply more push.

Student 4: I agree.

Student 5: Me too.

Researcher: Any other ideas?

Student 3: It should be the same because the bulbs use the same amount of energy.

Researcher: How about voltage in circuits 2 and 4?

Student 5: It should be the same because there are two cells in both circuits.

Student 2: Yes, it should be the same.

Researcher: How about the others?

(All the students predicted that the voltage in circuits 2 and 4 to be the same.)

Researcher: Set up the circuit and measure the voltage.

Student 1: Oh! The voltage in circuits 1 and 4 are the same. 
Student 3: Circuit 1 and 4 are $1.45 \mathrm{~V}$ and circuit 2 is $2.9 \mathrm{~V}$.

Student 2 Miss, it is the strength of the pump. Two pumps (batteries) connected in series means the pump is more powerful. Two pumps connected in parallel are of the same power. The strength is not increased.

Student 1: That means voltage across the batteries is not only concerned with the number of batteries.

Student 5: Look! I think maybe we should consider whether the batteries are connected in series or in parallel.

Student 3: Yes, if they are connected in series, voltage in the circuit is the sum of voltage in each cell. If it is connected in parallel, it is the same.

In lesson 2, it was surprising to note that students had a clear concept of resistance. They said

'Resistance is to hinder the flow of electrons.' As the discussion went on, the students used water pipes to explain the resistance of the bulbs and the flow of water in explaining the current

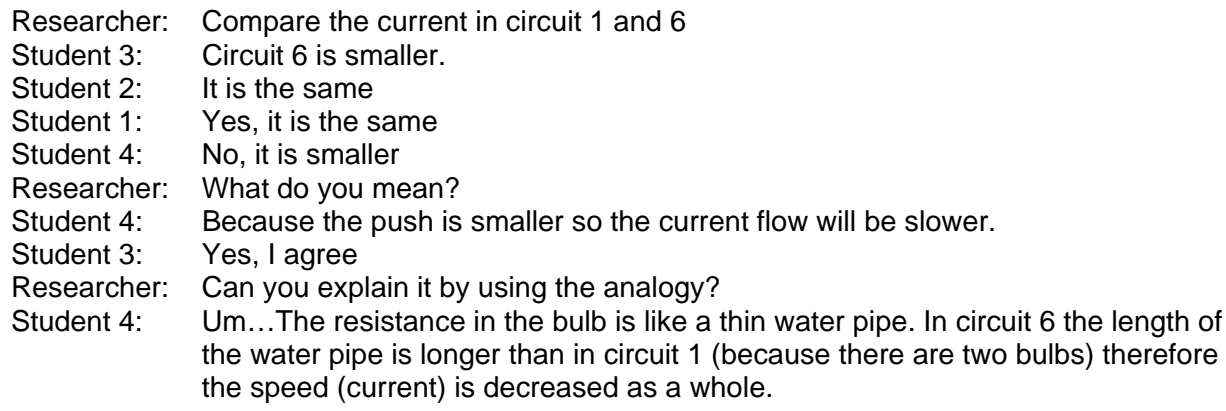

Student 4: Um...The resistance in the bulb is like a thin water pipe. In circuit 6 the length of the water pipe is longer than in circuit 1 (because there are two bulbs) therefore the speed (current) is decreased as a whole.

During the entire session, the students used the water analogy to explain the circuit phenomena without any difficulty.

In lesson 3, By plotting a graph of voltage against current, students realized that voltage and current were in direct proportions. After being introduced to Ohm's Law, the students were able to find the equivalent resistance in a series and parallel circuit without any difficulty.

In lesson 4, it was discovered that the students did focus their attention on voltage and saw the circuit as a whole system when solving circuitry problems. They first found out the voltage across the circuit components and then apply Ohm's law to find the current and the total resistance in the circuit. Students could solve the problems correctly. However, one of the students still put the focus on current when solving one of the problems and he soon realized that he needed to put the focus on voltage during the co-construction process in the group discussion. An excerpt of the discussion is included below:

Student 1: In circuit 9, bulb A and B are with the same brightness. In circuit 14 the total resistance is $2.3 \Omega$. The current is $1.5 \div 2 / 3=2.25 \mathrm{~A}$. In circuit 14 there are two branches so each branches is $1.125 \mathrm{~A}$ and in circuit 9 it is $1.5 \mathrm{~A}$ so bulb $\mathrm{A}$ in circuit 14 is dimmer.

Student 2: No the resistance in each branch is not the same. How come the currents will the same? I do not agree with you.

Student1: Ah! Yes, ...um..Let me think for a while.

Student4: I know.

Researcher: Yes, what? 
Student4: The voltage across bulb A in both circuits is the same. It is $1.5 \mathrm{~V}$.

Student1: yes, I agree. Oh! Some amendment on my answer. Voltage across bulb a is 1.5 so current in bulb $\mathrm{A}$ is $1.5 \mathrm{~A}$ because $1.5 \mathrm{~V} / 1 \Omega$ and voltage across bulb $\mathrm{B}$ and $\mathrm{c}$ is $1.5 \mathrm{~V}$ so current in bulb $\mathrm{B}$ and $\mathrm{C}$ is $1.5 / 2=.75 \mathrm{~A}$. As a result bulb $\mathrm{A}$ is no change and bulb $\mathrm{B}$ is dimmer.

[Insert circuit 9 and 14]

Results of the pre-test and post-test

The pencil and paper test provides a general picture of the students' performance and acts as a crude indicator to show whether the teaching strategy has been successful in bringing about conceptual change or not. The results of the pre- and post- tests are shown in Table 2.

[Insert table 2 about here]

The results of the pre-test indicated that the students' test performance were rather poor, with 5 out of 6 students getting only less than $20 \%$ correct and none of them reaching $40 \%$. It was thus very pleasing indeed to find that in the post-test, the minimum score achieved was 56\% and half of the students gained a perfect score. Further, a comparison of the results in Tables 1 and 2 revealed that the post-test results of this group of students out-perform that of the secondary 6 students in study 1 who had received the relevant instruction about elementary circuit theory as part of the regular science curriculum. The mean post-test score for this secondary 4 student group was $88.3 \%$, while that for the secondary 6 group in Study 1 was only $51.8 \%$ and none of the latter group achieved a perfect score. This provides some evidence that the teaching strategy used has been successful in promoting conceptual change in the students.

\section{Changes in students' explanations}

Examining the subjects’ verbal explanations used by the students before and after the lesson sequence provides another lens for scrutinizing whether conceptual change has taken place. 
There were many instances of distinct changes in reasoning used by the same student for the same question in the paper and pencil test in the interviews conducted before and after the teaching took place. The following are some typical excerpts:

Student 2, on question 3a (appendix D) about speed of motor if a bulb is added in series: before teaching: "The speed of the motor will not be affected because no current is used up yet."

after teaching: "The speed will be affected because the total resistance is larger and so the speed of the motor becomes smaller.

Student 3, on question 4 (appendix D) about current in a bulb when another bulb connected to it in parallel is removed:

before teaching: "Bulb A becomes brighter because it gets all the current." after teaching: "Bulb A remains the same as before because voltage across bulb $\mathrm{A}$ is the same.”

Student 6, on question 3c (appendix D) about brightness of bulb when connected in series to a motor in two different circuit locations:

before teaching: "The bulb in circuit 4 is brighter. It is because in circuit 5 some current is used by the motor."

after teaching: "The brightness of the bulb in both circuits is the same because the total resistance is the same and the voltage remained unchanged."

In the above examples, the students were found to have moved from reasoning using matter ontology to using constraint based interactions. As in Study 1, a systematic coding of all the 
predicates used in the pre-test and post-test interviews was conducted according to their ontological categorization. The inter-rater reliability for the coding exercises were found to be very high: $82.14 \%$ for the coding of the pre-test interview and $91.6 \%$ for the coding of the post-test interview. It is clear from the results presented in Fig. 6 that the improvement in test performance is accompanied by a remarkable swing towards using CBI reasoning in the explanations provided by the students. As with the results in Study 1, there is a clear relationship exhibited between the test performance and the percentage of expressed concepts categorized as CBI. It is thus a fair conclusion to draw from these results that the teaching sequence was successful in bringing about a conceptual change in the students both in terms of test performance as well as in the reasoning used by the students. The latter is a far more significant and reliable indicator that conceptual change has taken place.

It is in fact most remarkable to observe the sophistication and fluency with which some of the students were able to use constraint-based interaction analysis in working out the answers to some rather complicated problems. For instance, in working out the comparative brightness of the 5 bulbs in the circuit shown in Fig. 7, one of the students reasoned as follows:

The brightness of the bulbs should be $A=B>C>D=E$.

Assuming that the main current is $1 \mathrm{~A}$ and current flowing in bulbs $A$ and $B$ is $0.5 A$.

Then the total resistance of bulbs $C, D$ and $E$ is $2 / 3 \Omega$. Um... it should be $C>A=B>D=E$ because the resistance of bulb $C, D$ and $E$ is larger than that of bulbs $A$ and $B$. Therefore, voltage across bulbs $C, D$ and $E$ is larger. The voltage across bulbs $A$ and $B$ is smaller. Furthermore bulb D and E need to share the voltage.

At the beginning I think current flows from the positive terminal and is used up but I discovered that current is not used up and hence we need to focus on voltage. 
[Insert figure 6,7 about here]

\section{Effectiveness of the teaching strategy}

The results of the post-test showed that all six students achieved significant improvements in the test performance after the teaching intervention. Students 1,3 and 6 achieved a perfect score and student 2 committed one careless mistake. Further analysis of the interview protocol revealed that the other two students at times still focussed their attention on current and employed sequential reasoning, leading to wrong answers. Evidence is shown as follows:

\footnotetext{
' Bulb A will become brighter if bulb $B$ is damaged. To elaborate further, if there is $6 \mathrm{~V}$ across the battery, then bulb $A$ and bulb $B$... Um... I am wrong. It should be the current is $6 \mathrm{~A}$ in the main loop. Then bulb $A$ and bulb $B$ get $3 A$. If bulb $B$ is damaged, bulb A gets all the current.'
}

More work thus need to be done to help these two students to focus their thoughts on the concept of voltage.

The findings overall give us confidence in saying that the teaching strategy has been generally successful in promoting conceptual change in learning the concepts of electric circuits.

\section{Teaching for conceptual change and ontological change}

Based on the findings from the four reported studies as a whole, there are several implications that are important for planning teaching for conceptual change, some of which warrant further explorations: 
First, from the studies we note that students do hold a number of alternative conceptions before and even after formal instruction. As Nussbaum and Novick (1981) suggested nearly 20 years ago, teachers should not just look at them as a matter of not understanding the subject, but as a way of understanding that is different from what is intended. Therefore, teachers should be aware of these alternative conceptions and to take these as a starting point for planning and organizing teaching.

Second, a teaching program that builds on students' conceptions and involves them in predicting and modifying their own explanations appears to be useful in helping students to develop a higher level of understanding. These activities should be considered as a starting point for reasoning about electric circuits.

Third, the study revealed that students generally conceptualized electric current as matter. However, it has also been observed that teachers often use language in explanations such as 'Current comes out of the battery.', 'The sum of the current goes into a junction ...' which may reinforce this scientifically inappropriate conceptualization. It is important for teachers to pay attention to and promote a more precise use of language to help students discriminate the taught scientific conception from ones that they may intuitive hold.

Fourth, we found that when a modification was introduced in a certain part of an electric circuit, students usually neglected the 'global' change in the circuit. Therefore, we agree with Millar and King (1993, p.348) that "the 'global' effect should be an explicit teaching and learning objective at some stages in students' programme of study, where electric circuit ideas are concerned". Further, we recommend the use of qualitative questions such as 
comparing the brightness of bulbs between the same circuit or different circuits as these can encourage students to consider the relationship between various variables in the circuits.

Fifth, this "global perspective" necessary for understanding the relationship between various circuit variables is a necessary basis for exercising Chi et.al.'s constraint-based ontology in understanding scientific phenomena. The studies reported here provide further evidence in support of Chi et.al.'s theory that in order to promote conceptual change, students need to become acquainted with an understanding of constraint based interactions.

Sixth, it was found that just assuming a perspective of viewing circuitry interactions as constraint-based interactions is insufficient to help students to develop a scientific understanding of circuitry interactions. The choice of the right constraint as a focus is also crucial. In the case of electric circuits, students have to be guided to focus on voltage as the constraint rather than current for the development of the appropriate conception. Thus this set of studies have provided evidence that Chi et. al.'s framework probably needs to be further refined to include the selection of particular constraints as focus for particular conceptual domains as necessary conditions for designing effective teaching programs for conceptual change.

Seventh, in order that teachers can design teaching strategies that help students to focus their attention on the proper constraint, they need to be aware of the specific constraint that students' attention should be guided to focus on. This is at least the case found for learning about electric circuits. It thus of great interest and importance that further work be done to find out whether the same conditions apply to bring about conceptual change in other conceptual domain areas and also whether the selection of the appropriate constraint of focus 
is something that can only be empirically ascertained or whether there are more general characteristics that can be used to aid this selection.

\section{Conclusion}

In summary, the result from the four studies indicated that students' alternative conceptions on electric circuits are matter-based and exist across ages. We have demonstrated that concepts on electric circuits can be effectively learned by helping students to focus on the concept of voltage as the key constraint in an essentially constraint-based paradigm. Further, these studies also showed that in order to bring about conceptual change effectively, students should not only be given some knowledge of the CBI ontology but also need to be guided to focus on the appropriate constraint. It is hoped that findings in this study may shed light on designing the instructional strategies for conceptual change and provides an empirical data for further in-depth investigation of students' thinking processes.

\section{References}

Brown, D. (1987). Using analogies and examples to help students overcome misconceptions in physics: A comparison of two teaching strategies. Unpublished doctoral dissertation, University of Massachusetts.

Carmichael, P., Watts, M., Driver, R., Holding, B., Philips, I. \& Twigger, D. (1990). Research on students' conceptions in science: A bibliography. Leeds,England: Children's Learning in Science Research Group. (University of Leeds).

Champagne, A. B., Gunstone, R. F., \& Klopfer, L. E. (1985). Effecting changes in cognitive structures among physics students. In L. H. T. West \& A. L. Pine (Eds.), Cognitive structures and conceptual change (Orlando, Fl: Academic), 163-187 
Chi, M. H. T. (1992). Conceptual change within and across ontological categories: Examples from learning and discovery in science. In R. N. Giene (ed.) Cognitive models of science (Minneapolis MN: University of Minnesota Press), 1129-1187.

Chi, M. H.T. (1993) Barriers to conceptual change in learning science concepts: A theoretical conjecture. In Proceedings of the Fifteenth Annual Conference of Cognitive Science Society. (Hillsdale, N.J. : Lawrence Erlbaum Associates), 312-317.

Chi, M. T. H., Slotta, J. D., \& de Leeuw, N. (1994). From things to processes: A theory of conceptual change for learning science concepts. Learning and Instruction $\mathbf{2} 4$, 27-43.

Clement, J. (1987). Overcoming students' misconceptions in Physics: The role of anchoring intuitions and analogical validity. In J. D. Novak (Ed.) Proceedings of the second International Seminar Misconceptions and Educational Strategies in Science and Mathematics. (Ithaca, Nk: Cornell University), 84-97.

Clement, J. (1993). Using bridging analogies and anchoring intuitions to deal with students' preconceptions in physics. Journal of Research in Science Teaching, 30, 1241-1257.

Cosgrove, M. (1983). Electric current developing the concept. Extension unit one. Science Education Research Unit. Working paper 208. University of Waikato, (Hamilton, N.Z).

Cosgrove, M. (1995). A study of science-in -the- making as students generate an analogy for electricity. International Journal of Science Education, 17(3) 295-310.

Dreyfus, A., Jungwirth, E., \& Eliovitch, R. (1990). Applying the 'Cognitive conflict' strategy for conceptual change. Some implications, difficulties and problems. Science Education, 74, 555-569.

Driver, R. \& Easley, J. (1978) Pupil and paradigms: A review of the literature related to concept development in adolescent science students. Studies in Science Education, 5,6184.

Gilbert, J., Osborne, R., \& Fensham, P. (1982). Children’s science and its consequences for teaching. Science Education, 66, 623-633.

Gentner, D., \& Genter, D. R. (1983). Flowing waters or teaming crowd: mental model of electricity. In D. Gentner \& A. L. Stevens (Eds.), Mental Models (Hillsdale, NJ: Erlbaum), 99-129.

Helm, H. (1980) Misconceptions in Physics amongst South African Students. Physics Education, 15(2), 92-97.

Hewitt, P. G., (1987) Conceptual Physics. Menlo Park, CA: Addison, Wesley.

Law, N. (1991). What can we assume learners to know when we start teaching introductory circuit theory? Proceedings of the Australian Association for Engineering Education Third Annual Conference, Adelaide, 15-18 December 
Lawson, A. (1993). The importance of analogy: A prelude to the special issue. Journal of Research in Science Teaching, 30, 1213-1214.

Millar, R.,\& King, T. (1993). Student understanding of voltage in simple series electric circuit. International Journal of Science Education, 15(3) 339-349.

Novak, J. D(1977). A Theory of education. Ithaca, NY: Cornell University press.

Nussbaum, J., \& Novick, S. (1981). Creating cognitive dissonance between students' preconceptions to encourage individual cognitive accommodation and a group cooperative construction of a scientific model. Paper presented at the American Educational Research Association Annual Convention, Los Angles.

Pfundt, H, \& Duit, R. (1991). Bibliography: Students' alternative frameworks and science education. Kiel, Gen. University of Kiel Institute for Science Education.

Posner, G., Strike, K., Hewson, P., \& Gertzog, W. (1982). Accommodation of a scientific conception: Toward a theory of conceptual change. Science Education, 66, 211-227.

Shipstone, D. M. (1984). A study of children's understanding of electricity in simple DC circuits. European Journal of Science Education, 6(2) 185-198.

Slotta, J., \& Chi, M.T.H. (1996). Understanding Constraint Based Processes: A precursor to conceptual change in Physics. In G.W. Cottrell (Ed.), Proceedings of the Eighteeth Annual Conference of the Cognitive Science Society, Mahwah, NJ: Erlbaum, 306-311.

Slotta, J., Chi, M. T. H. \& Joram, E. (1995). Assessing student' misconceptions of physics concepts: An ontological basis for conceptual change. Cognition and Instruction, 13 (3) $373-400$.

Treagust, D. F. (1995). Enhancing students' understanding of science using analogies. In B. Hand \& V. Prain (Eds.), Teaching and learning in science: The constructivist classroom (Harcourt Brace \& company), 44-62.

Wandersee, J.H., Mintzes, J.J. and Novak, J.D.(1994) Research on alternative conceptions in science. In D.L. Gabel (Eds.), Handbook of research on science teaching and learning, Macmillan, 177-210.

Wang, T. Y. \& Andre, T. (1991). Conceptual change text versus traditional text and application question versus no questions in learning about electricity. Contemporary Educational Psychology, 16,103-116.

White, R \& Gunstone, R. (1992). Probing understanding. London: The Falmer Press. 
Table 1 Students' test scores in Study 1.

\begin{tabular}{|c|c|}
\hline Subject & \% of the answers correct \\
\hline S1 & 85.70 \\
\hline S2 & 62.50 \\
\hline S3 & 43.75 \\
\hline S4 & 50.00 \\
\hline S5 & 43.75 \\
\hline S6 & 25.00 \\
\hline
\end{tabular}


Table 2. The pre-test and post-test results in Study 4

\begin{tabular}{|c|c|c|}
\hline & Pre-test score (\%) & Post-test score (\%) \\
\hline Student 1 & 18.75 & 100.00 \\
\hline Student 2 & 6.25 & 93.75 \\
\hline Student 3 & 37.50 & 100.00 \\
\hline Student 4 & 12.50 & 62.50 \\
\hline Student 5 & 6.25 & 56.25 \\
\hline Student 6 & 12.50 & 100.00 \\
\hline
\end{tabular}




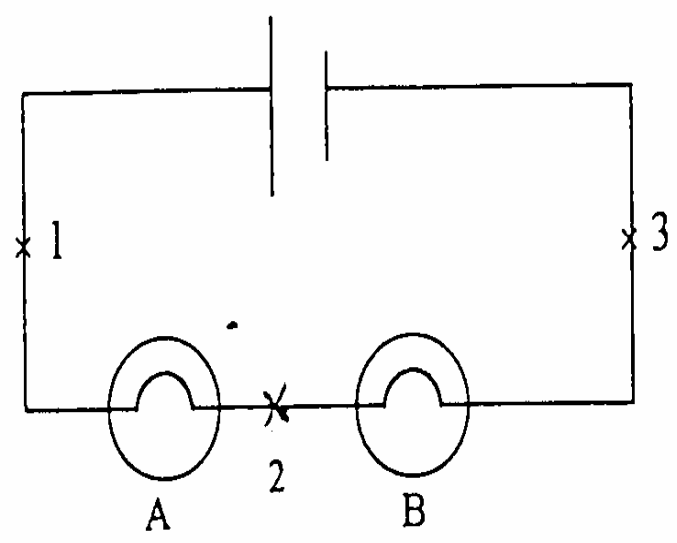

Figure 1

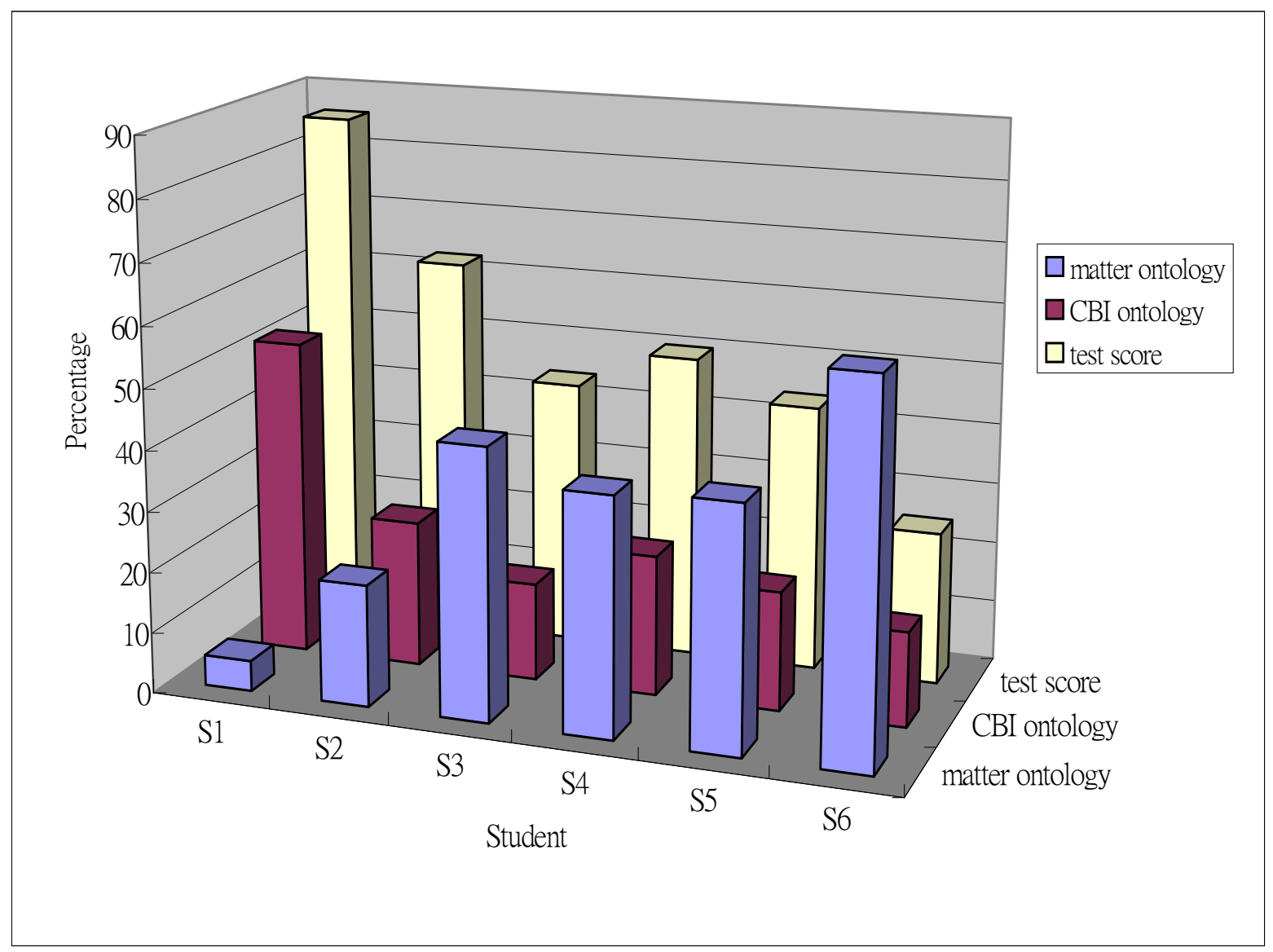

Figure. 2 Chart showing the test score and percentage of ontological categories of expressed concepts for the six students in Study 1 


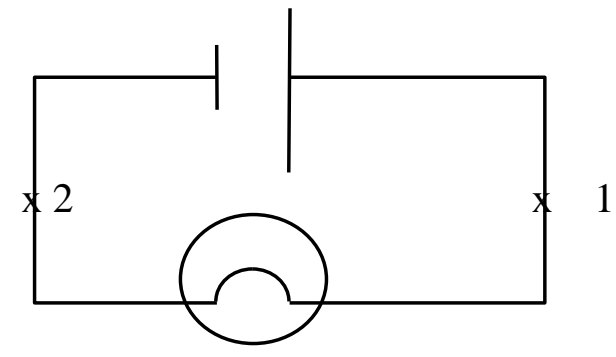

A

Figure 3
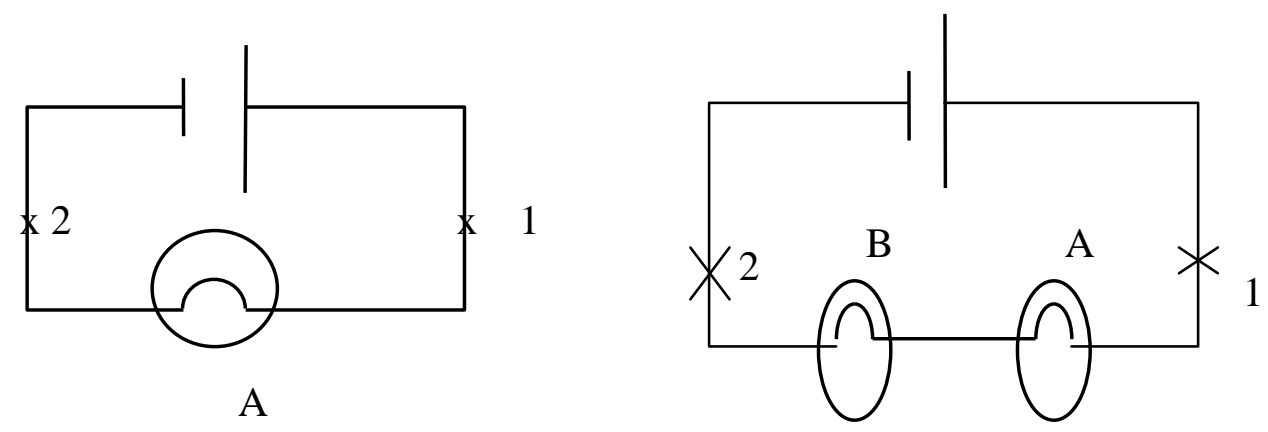

Circuit 1

$\underline{\text { Circuit2 }}$

Figure 4 


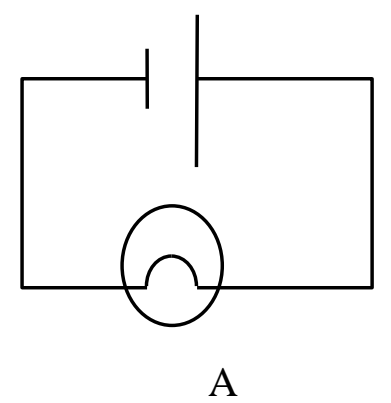

Circuit 1

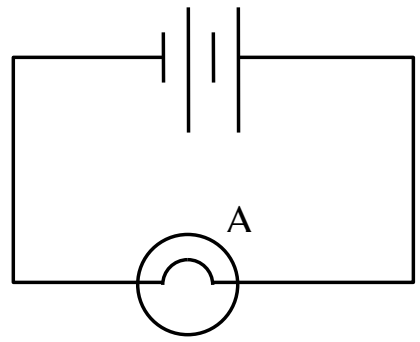

Circuit 2

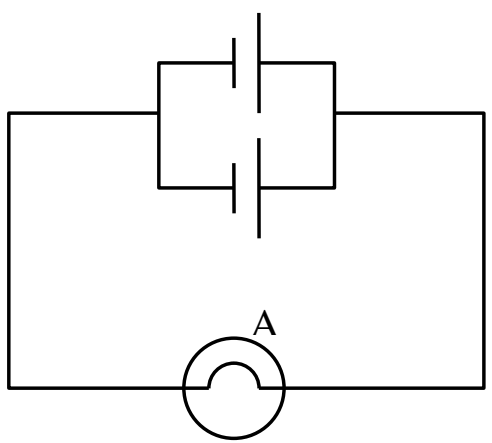

Circuit 4

Figure 5 


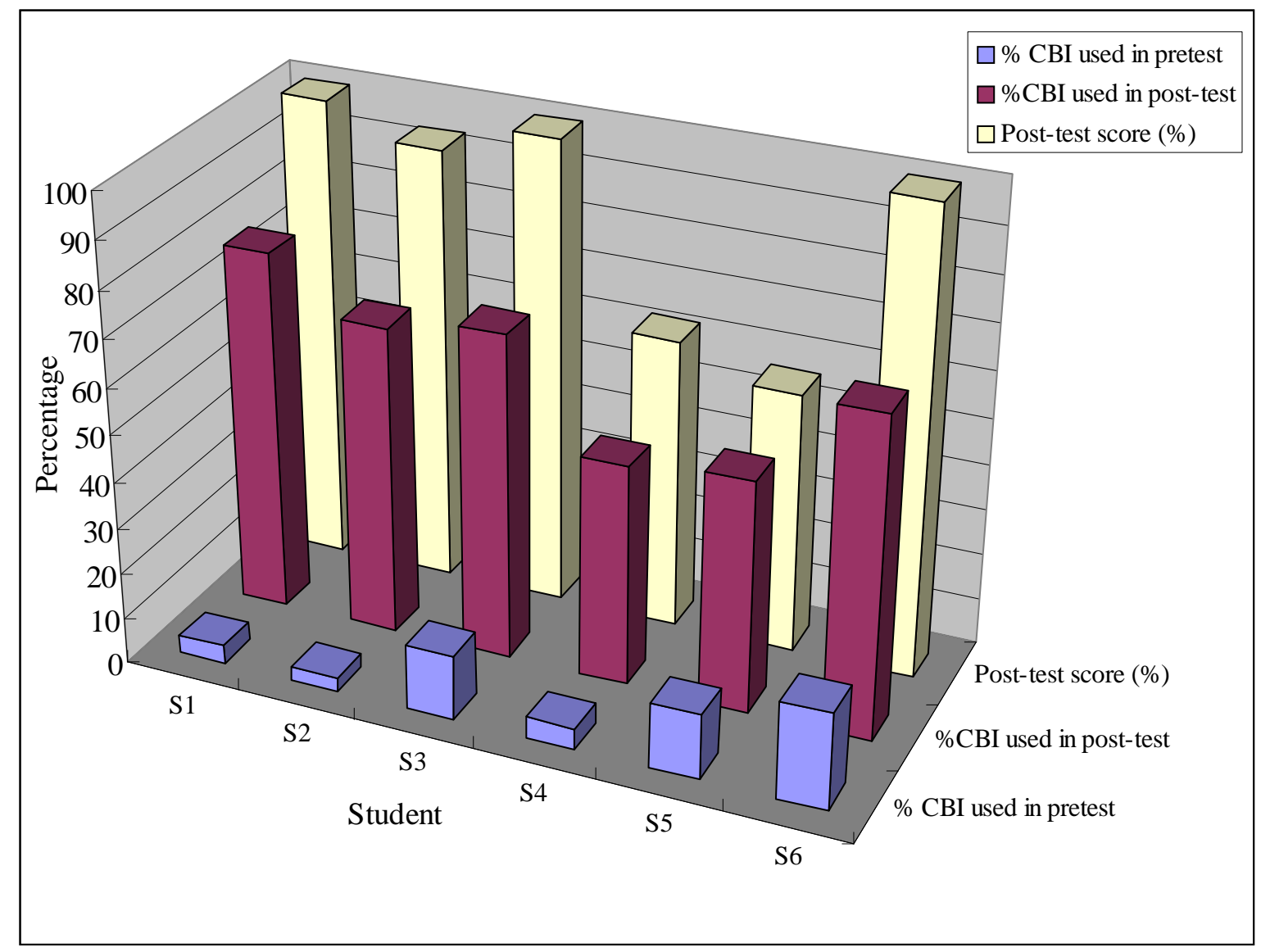

Figure.6 Chart showing the post-test scores and the percentage of CBI used in the pre-test and post-test interviews. 


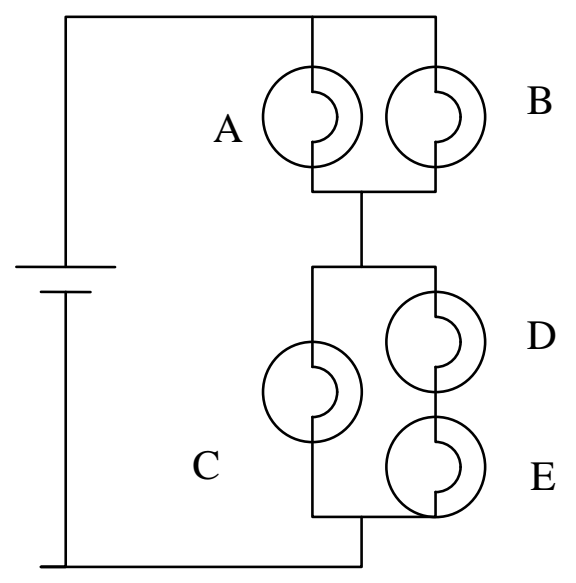

Figure. 7 